\title{
Integration of China and the West: Diversified Expression of Contemporary Chinese Local Oil Painting
}

\author{
Shihua Wu, Hong Yang \\ Sichuan University of Arts and Sciences, Chengdu, China \\ Email: wshh0018@163.com
}

How to cite this paper: $\mathrm{Wu}, \mathrm{S}$.H. and Yang, H. (2019) Integration of China and the West: Diversified Expression of Contemporary Chinese Local Oil Painting. Open Access Library Journal, 6: e5818.

https://doi.org/10.4236/oalib.1105818

Received: September 25, 2019

Accepted: October 20, 2019

Published: October 23, 2019

Copyright $\odot 2019$ by author(s) and Open Access Library Inc.

This work is licensed under the Creative Commons Attribution International License (CC BY 4.0).

http://creativecommons.org/licenses/by/4.0/

\section{(c) (i) Open Access}

\begin{abstract}
Chinese native oil painting inherits and develops in the exchanges and collisions of eastern and western cultures. Influenced by Chinese traditional culture, the realistic expression form of western traditional realism has evolved into diversified expression mode. Under the background of cultural renaissance in China, analyzing the diversified expression mode in the localization process of contemporary local oil painting will help the inheritance and development of contemporary local oil painting.
\end{abstract}

\section{Subject Areas}

Art

\section{Keywords}

Local Oil Painting, Cultural Renaissance, Expression Form, Nationality, Integration

\section{Research Background}

As a foreign art form, local oil painting has experienced the imitation of Western oil painting formal language and the localization of artistic expression. After entering the 21st century, China has ushered a period of rapid development in many aspects after the reform and opening up, and has basically completed modernization in the fields of industry, agriculture, and national defense etc. The gradual strengthening of the social economy and the continuous improvement of the national political system have pushed China to a great national renaissance, and the diversified forms of artistic creation in the cultural field have embraced the era of cultural renaissance also, as a result, literary and artistic cre- 
ation tend to be confident in the national traditional culture. In this context, exploring the relationship between the diversified performance of local oil painting and the Western art form, national traditional culture and the context of the times can not only be beneficial to search the inheritance and development mode of local oil painting, but also help to study the practical significance of the integration of Chinese and Western culture and art.

\section{The Development Course of Chinese Local Oil Painting}

If we sort out the development process of Chinese oil painting, its origin would be in the period of the Republic of China. At that time, some painters had a certain understanding of the expression of oil painting from technical materials to expression forms through studying abroad. For example, Lu Sibai's Portraits of farmers (see Figure 1), Wang Yuezhi's Pictures of abandoned people, Tang Yihe's Grandfather and grandson and other works are representatives of this period. Due to the political, economic and cultural environment, China was poor and backward in the world. Chinese local oil painting did not have a mature form of creative expression, nor did it have the aesthetic pleasure of the connotation of the works, It only was the spontaneous expression of the painter's life feelings which reflected the hardships and bitterness of the public life those days.

After the founding of new China, artists represented by Luo Gongliu and Wang Shikuo created a large number of works, thus Chinese local oil painting had been further developed. The painting language and expression form were all based on the artistic creation method of the Former Soviet Union which generally adopted realistic expression with relatively single painting technique. Since serving for the society was the purpose of artistic creation, so the people became

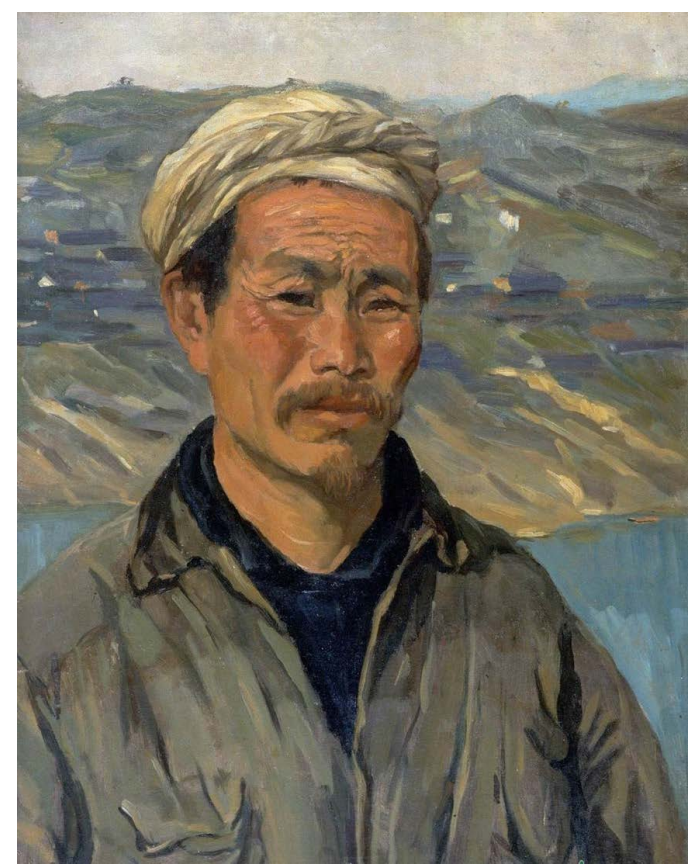

Figure 1. Lu Sibai, Sichuan farmer. 
the eulogy objects in the subject of local oil painting, and all the pictures were unified and full displayed the farmers' unique positive, industrious and tenacious spirit of that era. Although the realistic local oil painting has become an important form, there is no denying that it contains a political expression of collectivism but lacks the ontological language of traditional oil painting. Until the 1980s, under the reform and opening up Chinese oil painting ushered in the spring of creation, meanwhile the local oil painting rising in Sichuan became the mainstream of painting creation for a time. Influenced by diversifying contemporary western oil paintings, famous works such as Father, Spring breeze has awakened (see Figure 2) and Tibetan group painting expresses the spiritual needs of the times in different ways. In those days, because of the category of objective realism, local oil painting tried its best to construct simple humanitarian discourse around "human nature". The expression of painting returned to the reality of life and the sincerity of human nature, moreover, its language developed from imitation to mature by learning western oil painting ontology language. Therefore, no matter from the external form of painting, or the connotation of the spirit of painting, local oil painting in the 1980s has written an important page in the history of modern Chinese painting. After 85 fashion art, it entered the trough in the industrial modernization process. Since the 1990s, the expression of oil painting "on the one hand was horizontal exploring and expanding artistic concept and form along the development vein of western modern art; on the other hand, it studied and researched western traditional realistic painting on technique and language vertically and deeply" [1]. Local painters try to seek new aesthetic ideals and artistic propositions in silence and seek the national expression of oil painting in reflection on the phenomenon of local oil painting.

In the new era of cultural Renaissance, although the form and expression of art inevitably tend to be diversified, the local oil painting carries the aesthetic character of Oriental nations in its diversified expression. For example, the works

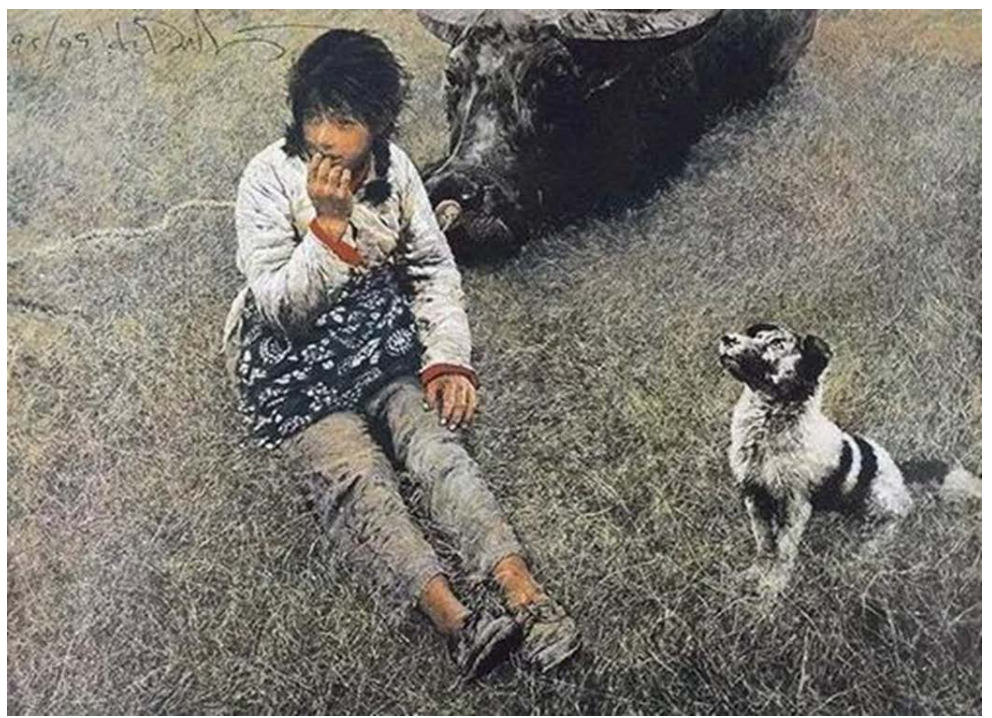

Figure 2. He Duoling, Spring breeze has awakened. 
of contemporary painters such as Zheng Yi, luo zhongli, Gong lilong, Wang Hongjian and Wang Yidong show the unique aesthetic connotation of Oriental traditional culture in diverse ways of expression. Undoubtedly, in the context of cultural Renaissance, the external expression and connotation of the works have gone beyond the painter's personal aesthetic pursuit and reflected the cultural characteristics of a nation in the way of visual art.

\section{Diversified Forms of Contemporary Local Oil Painting}

Under the influence of the integration and development of Chinese and western cultural and artistic forms, Chinese contemporary local oil painting is localized. The traditional national culture and diversified expression of world contemporary art greatly broaden the local themes and connotations under the category of realism. In the mid-1980s, Chinese rural oil painting gradually shifted from the rural realism that reproduced the current situation of Chinese countryside to the diversified development trend. [2] In the context of modern Chinese culture, the expression forms of local oil painting deduced the diversity of artistic expressive styles from traditional realism, such as the classical expression, local expressionism, new realistic local painting and local symbolism, etc.

1) Classical expression of local oil painting. Classical painting which mostly takes religion, mythology or historical events as themes began in the Renaissance era of Europe. It has taken the rural life at the bottom of society as its subject matter since its emergence. It seems that classical and rural cannot be connected in any case. However, in the exploration of the localization of local oil painting in China, the painters integrated and developed them to form a new aesthetic expression. For example, in Wang Yidong's series of Yimeng (see Figure 3) native paintings, characters in pictures are rigorous modeled in delicate ways, while the colors which reflect Chinese traditional culture are in pursuit of subtle changes in simple contrast. Clearly the expression of work language belongs to the category of classicism, but neither is it a paean to the classical spirit, nor a copy of the traditional classical technology. Under Chinese traditional culture aesthetic interest, the painter draws lessons from Chinese traditional painting

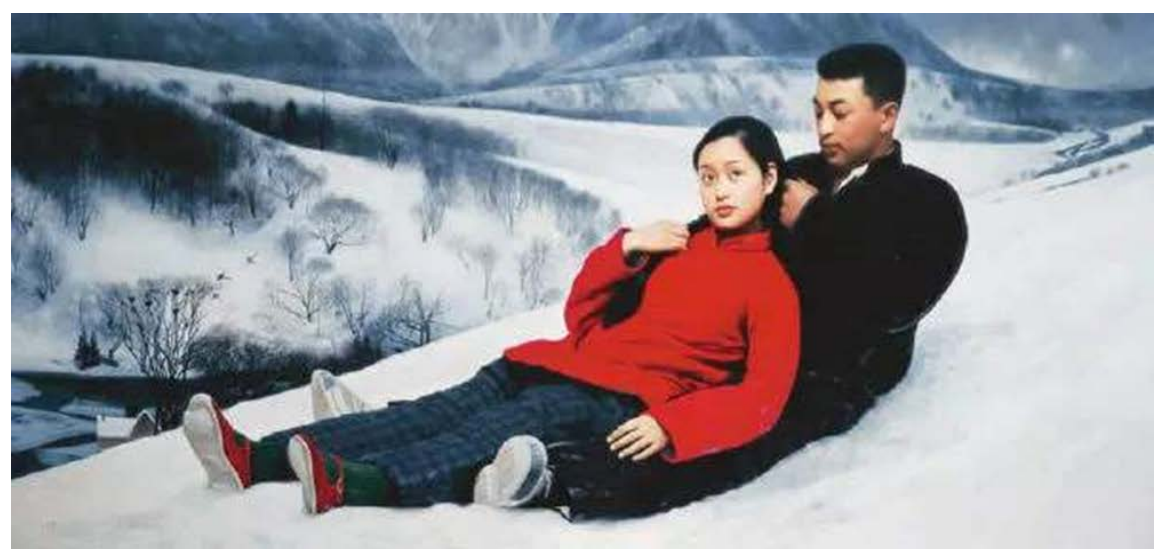

Figure 3. Wang Yidong, Series of Yimeng. 
techniques in Jimo and folk color contrast technique, furthermore, he expresses the local folklore theme of lower Riba people in an aesthetic and classical way and in visual expressions a new local aesthetic implication can be seen.

2) Expressionism of local oil painting. Expressionism, as a form of modern western painting, often uses exaggerated, deformed shapes and strong emotional colors to emphasize the spiritual expression of the painter himself. Compared with Chinese freehand brushwork, it is not difficult to find the same emotional expression of the painters. The modern local oil painters generally take local themes as the carrier of emotional expression in their creation, meanwhile the elements such as texture, brushwork, thickness contrast, image or color are used to create subjective emotions of the picture. Luo Zhongli and Duan Zhengqu deserve to be the representatives of the expressionism in contemporary Chinese local oil painting. Their works such as, Ba Shan series, Yellow River rhyme and Oriental Red have thick and bold strokes, strong colors, simple and exaggerated shapes. This way of expression introduces the audience to the emotional atmosphere beyond the objective and real representation of life, it pursues the strong local national spirit in the plain, primitive and sincere language. The visual presentation is the expressionism of western oil painting, if we make an in-depth analysis of the performance factors, obviously it is not the artist's simple individual emotional catharsis but Chinese traditional folk culture has an important influence on it, modeling means and color system of the folk fine arts used in the creation make oil painting branded nationality features.

3) The symbolism of local oil painting. Symbolism is the expressive style of modern western painting. In the unreal and objective portrayal, the painter conveys the specific meaning of the objects and images in his works while gives enlightenment to the viewer's thinking through metaphor and symbol. The modern local oil painters in China also use this artistic expression to sublimate the spiritual connotation of their works. In Gong Lilong's works such as Fly, Packed grain stalks, he displays humorous, exaggerated and humorous aesthetic in the visual, meanwhile the colors of the paintings are usually connected with traditional folk art color, so no matter from the works of modeling, or scene narrative and color it revealed a symbolic meaning. Another example is the series of Catching in the rye created by Wei Ershen, the specific movements, expressions of the characters and yellow tones all have directionality meaning from which we can understand that the painter watched the spiritual home of "intellectuals" persistently in the non-real and absurd time and space of the countryside. It can be seen that the spiritual connotation carried by paintings has different symbolic meanings in different cultural contexts which are often connected with national culture, and it is the natural revelation of the national aesthetic of local oil painting.

4) Rural surrealism. Surrealism, as an art form of modern painting, usually presents the images that transcend time and space and expresses the deep meaning in the visual view of non-objective real life. Chinese contemporary local artists use this expression mode to introduce local oil painting into new visual 
perception. Chen Shuzhong's Wild grass beach series (see Figure 4) adopts this way either. The modeling ratio between images is not the true reproduction of life. Exaggerated still life modeling, environment and simple character images make the picture itself no longer limited to the reproduction of life. The works which devoted to the description of objects in detail and construct absurd, bizarre and humorous plots in the narrative of rural life, present people, objects or events across time and space to the audience. Of course, the plot narrative of the picture is closely connected with life. Painters even deliberately narrate historical scenes such as production, entertainment and life in contemporary society with dramatic plots to enhance the artistic tension, so that the audience can think deeply about the spiritual connotation behind the works in reasonable but unreasonable pictures.

5) The new realism expression of local oil painting. Realism is the way of painting expression that has been used since the birth of rural oil painting. From Bruegel of the Netherlands to Miller in the 19th century to the present rural oil painting, the realistic expression has been continuously developed along with the development of painting. Realism which expresses the rural environment and social spirit of the times with objective and true records conveys true feelings through typical people and things. Such as painter Zheng Yi, he tried to reflect the ideological changes of rural farmers in the new era under the objective and real representation. In Burning heart has flown, he tried his best to depict the farmers' working scene in a real way so as to express that the social progress and development inevitably affect the inner feelings of peasants in the process of urbanization in China, and people who left behind in the countryside are flying in the center of complex thoughts. Chen Anjian's Tea house series nowadays still

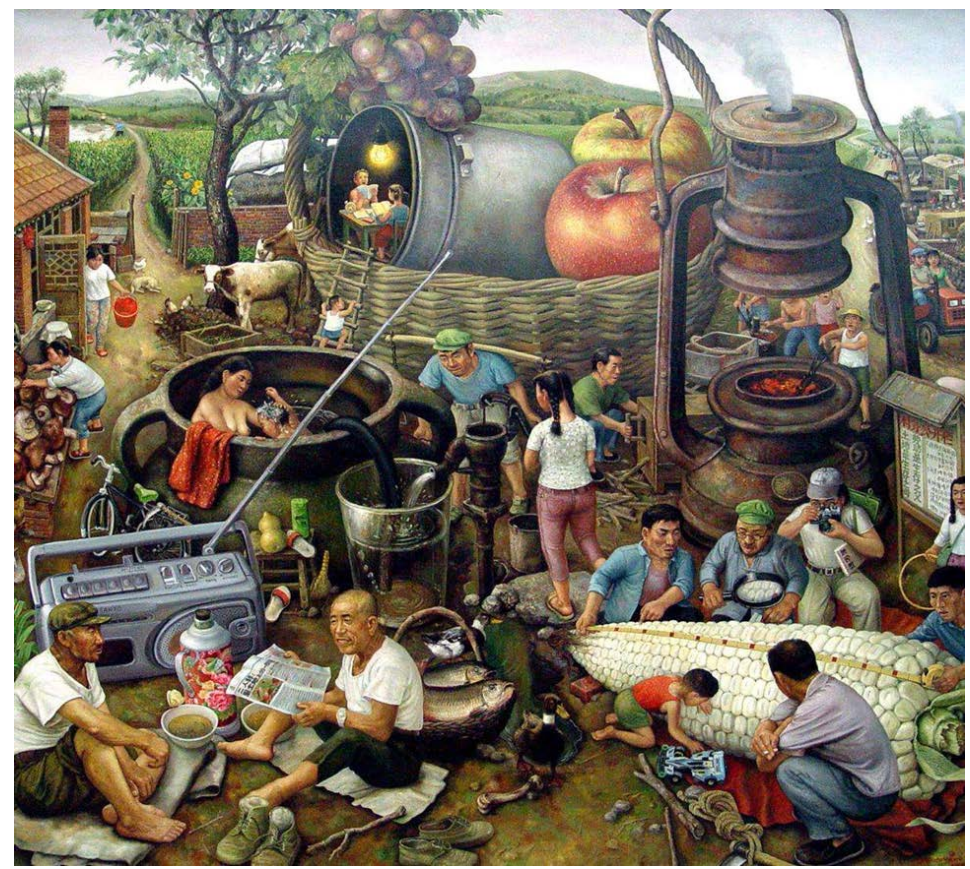

Figure 4. Chen Shuzhong, Wild grass beach series. 
adopts 1980 's photographic representation which is inseparable from the depiction of tedious details. In the flat, old, familiar, warm and humorous pictures, he seems reluctant to let go of a trace of message. Simplicity of picture composition and complicated detail characterization coexist in one picture which highlights the spirit of optimism, comedy and liveliness of farmers. For Wang Hongjian, his realistic style has always been expressing rich focal spiritual connotations in the realistic reproduction of the objective objects. Such as The winter sacrifice expresses the torture of ordinary people's life meaning and reveals the painter's attitude towards life as well. As a matter of fact, contemporary local painters are impossible to confine their creation to a certain way of expression, so they often show rich and diverse characteristics in the mutual learning and integration of aesthetic cultural orientation.

\section{The Value of Diversified Expression of Local Oil Painting}

The development history of local oil painting in China shows that the cultural context of the times, contemporary art form, traditional oil painting language and national traditional culture inevitably affect the inheritance and development of local oil painting. The reason why oil painting can be accepted by hundreds of millions of Chinese and become an important part of Chinese modern culture is that it has initially formed its basic linguistic form of expression in the course of its development, and the realistic spirit and national spirit connotation it revealed. [3] For contemporary Chinese local oil painting, if the traditional language is the root of its adherence, the western modern art expression is the form of innovative expression for reference, Chinese national traditional culture is undoubtedly its spiritual connotation. [4] Its diversified expression forms are based on the western oil painting artistic expression forms. Incorporating elements of national culture in traditional oil painting language and advocating the new aesthetic ideals in the painting expression, the localization of oil painting is explored in the integration of Chinese and western cultures. No doubt, the localization and times of Chinese local oil painting have gone beyond the pursuit of individual or painting school and become the conscious consciousness and common ideal of local artists.

Under the background of cultural Renaissance, Chinese contemporary local oil painting constructs the national characteristics of painting in the aspects of subject matter, language and expression technique, etc., but the diversified expression mode can highlight the national significance in China. On the one hand, Chinese oil painting originated from the Eastern spread of Western learning ,as a result the fusion of Chinese and western forms not only has created the diversity of Chinese contemporary painting expression, but also has led the local oil painting expression from single realism to multiple expressions, and moreover, it embodies the worldwide nature of oil painting art under the globalization of global culture as well as promotes the development of inheritance of traditional local painting. On the other hand, Chinese contemporary local oil paint- 
ing's external expression contains unique Oriental aesthetic connotation. Seen from the surface of painting images, though it uses western form of expression but it actually carries the national characteristics of eastern culture. If examining the different expressions of contemporary local oil painting, such as classicism, expressionism and symbolism, we'll find that they are all related to traditional Chinese culture. Some are associated with external images such as schema, subject matter, technique and composition, or contain the spirit of national local culture in the connotation. Thus we can say that the diversified expression of contemporary local oil painting not only enriches the form of painting but also further conveys new national aesthetic propositions in the visual expression of painting.

\section{Conclusion}

In the new era of cultural rejuvenation, local culture will be carried forward as the foundation of Chinese traditional culture. As an art form that expresses local culture, local oil painting will surely usher in a flourishing opportunity in the new era. Under the care of the cultural context of the times, Chinese local oil paintings which have evolved from a simple imitation of Western oil paintings to a diversity of Eastern national aesthetics are undoubtedly the crystallization of the blending of Chinese and Western cultures. It can be seen that the inheritance and development of contemporary Chinese local oil painting are inseparable from the integration of Chinese and Western culture. On the one hand, it needs to adhere to the traditional language of Western oil painting. On the other hand, it needs to absorb nutrition in the traditional culture of Chinese nation and folk. In a word, we should explore the national quality of local oil painting in the collision of Chinese and Western culture.

\section{Conflicts of Interest}

The authors declare no conflicts of interest regarding the publication of this paper.

\section{References}

[1] Zan, J.J. (2006) Consciously Constructing the Chinese School of Oil Painting Art. Mei Yuan, No. 1, 6.

[2] Niu, Z.X. (2008) Analysis of the Development of Contemporary Chinese Local Oil Painting. Journal of Chifeng University, No. 3, 155.

[3] Zhao, J. (2018) Reflections on the Development of Chinese Oil Painting. Journal of Yunnan Academy of Art, No. 3, 11.

[4] Sun, X.H. (2012) Foreign Countries and Tradition. Hundred Schools in Arts, No. 4, 219. 